\title{
Altemeier operation associated with dynamic graciloplasty: a case
} report

\author{
Massimo Mongardini, Roberto Paolo Iachetta*, Alessandra Cola, \\ Eleonora Degli Effetti and Filippo Custureri
}

Address: Department of Surgical Sciences, Division of General Surgery L, "Sapienza" University of Rome, Italy

Email: Massimo Mongardini - massimo.mongardini@uniroma1.it; Roberto Paolo Iachetta* - rpiachetta@gmail.com;

Alessandra Cola - alecola73@gmail.com; Eleonora Degli Effetti - ele80@tiscali.it; Filippo Custureri - filippo.custureri@uniroma1.it

* Corresponding author

Published: 4 December 2009

Journal of Medical Case Reports 2009, 3:9317 doi:10.1 I86/1752-1947-3-9317

Received: 3 August 2008

Accepted: 4 December 2009

This article is available from: http://www.jmedicalcasereports.com/content/3/1/9317

(C) 2009 Mongardini et al; licensee BioMed Central Ltd.

This is an Open Access article distributed under the terms of the Creative Commons Attribution License (http://creativecommons.org/licenses/by/2.0), which permits unrestricted use, distribution, and reproduction in any medium, provided the original work is properly cited.

\begin{abstract}
Introduction: More than $80 \%$ of patients with full-thickness rectal prolapse have co-existing fecal incontinence. Choosing the ideal surgical strategy is always a difficult task. We combined an Altemeier rectosigmoid resection with anal dynamic graciloplasty to provide a functional neosphincter. We found no published reports describing this surgical association.
\end{abstract}

Case presentation: We report the case of a 72-year-old Caucasian woman with full-thickness rectal prolapse associated with fecal incontinence from severe neuromuscular damage.

Conclusion: Combined dynamic graciloplasty and an Altemeier operation could be a valid therapeutic option in patients with severe rectal prolapse with fecal incontinence from severe neurogenic damage.

\section{Introduction}

More than $80 \%$ of patients with full-thickness rectal prolapse have co-existing fecal incontinence [1]. The physiopathology of this condition remains partly unknown. According to recent studies, ultrasonography documents a lesion involving the internal or external anal sphincter or both in $71 \%$ of patients, while in the remaining $29 \%$ incontinence arose from marked anorectal sphincter complex weakness related to severe pudendal neuropathy or to excessive internal sphincter inhibition secondary to the prolapse-associated chronic stimulation of the inhibitory anorectal reflex [2]. Choosing the ideal surgical strategy for managing prolapse-associated fecal incontinence is always a difficult task.

In a patient who presented recently with full-thickness rectal prolapse associated with fecal incontinence from severe neuromuscular damage, we combined an Altemeier rectosigmoid resection with anal dynamic graciloplasty to provide a functional neosphincter. This combined procedure has the advantage of avoiding the risk that correcting the rectal prolapse alone might lead to the removal of the terminal obstacle, namely the rectosigmoid intussusception, and thus worsening fecal incontinence.

\section{Case presentation}

We present the case of a 72-year-old Caucasian woman with a history of childhood encephalitis with motor sequelae, who presented with a 10-year history of fullthickness rectal prolapse that had progressively worsened despite two surgical procedures, namely, anal encirclement 13 years before presentation and a new encirclement associated with stapler mucous prolapsectomy 6 years 
before presentation. For 2 years, severe fecal incontinence associated with repeated rectal bleeding had prevented her from sitting down, had severely impeded her walking and induced pain. The patient's Wexner incontinence score was 19 , and anorectal manometry showed marked hypotonia of the anal canal at rest $(20 \mathrm{mmHg})$ and during contraction (40 mmHg). Endorectal ultrasonographic examination revealed no documentable sphincter lesions although the muscle fibers appeared markedly thinned. Electromyographic (EMG) recordings disclosed severe neurogenic damage to her external anal sphincter. The patient declined to undergo construction of a definitive colostomy.

The operation proceeded in three steps. First, the fullthickness rectal wall was incised circumferentially at $2 \mathrm{~cm}$ from the pectinate line. The pouch of Douglas was opened and about $20 \mathrm{~cm}$ of bowel was prepared before the peritoneal fossa was reconstructed. Once the bowel was resected a coloanal anastomosis was constructed with a 29 circular stapler. The operation proceeded with dynamic graciloplasty. Through two longitudinal incisions on the medial face of the right thigh, the gracile muscle was mobilized down to its insertion on the tibial tuberosity. Once the muscle was prepared for tunneling, electrical stimuli were delivered to identify the neurovascular peduncle. This step is crucial to identify the site for definitive intramuscular electrode implantation that guarantees an effective gracilis muscle contraction.

Second, the gracile muscle was tunnelled and wrapped around the sigmoid colon anastomosed to the residual rectum after preparing the peri-anastomotic space using two longitudinal perianal incisions. This fixed the muscle tendon on the perineal skin.

Finally, a subcutaneous pouch was created in the right iliac fossa to house the neurostimulator. The leads connecting the neurostimulator to the gracile muscle were then tunnelled subcutaneously. This entailed constructing a temporary transverse colostomy to minimize the risk of infections involving the perianal accesses that can damage the neosphincter or cause its disinsertion.

The patient had an uneventful postoperative course, and on day 7 began regular leg gymnastics with a soft balloon placed between her knees. Neurostimulation delivered at low frequency began on day 20 and continued for about 2 months before the frequency was increased. In the sixth month, clinical examination and manometric evaluation showed a slight improvement in sphincter tone, that is, pressure at $30 \mathrm{mmHg}$ without electrical stimulation and $55 \mathrm{mmHg}$ with electrical stimulation. One year after the operation, the colostomy was closed under manometric evaluation (pressure at $40 \mathrm{mmHg}$ without electrical stimulation and $65 \mathrm{mmHg}$ with electrical stimulation).
Two years after the combined operation, no further recurrent rectal prolapse was visible. The patient was already continent for solids (Wexner incontinence score 9) and could switch the pacemaker device on and off without help.

\section{Discussion}

We found no published reports describing the combined dynamic graciloplasty and Altemeier operation we used to treat this patient who had rectal prolapse associated with fecal incontinence. Although this association is a relatively common problem in older individuals, patients presenting with this socially distressing disorder are often severely debilitated and have often undergone various treatments that provided no meaningful results. It is thus important to select an individual management strategy from among the various therapeutic options that will improve fecal incontinence and improve the patient's quality of life.

The cause of our patient's complete rectal prolapse was unclear. Although its complex pathophysiology remains incompletely understood, major known causative factors include abnormalities of the pelvic floor, rapid reduction in adipose tissue in the ischiorectal fossa (an important factor in children) and obstructed defecation and psychic disturbance especially in older patients.

In this case, as in about $80 \%$ of known cases [1], the patient had full-thickness rectal prolapse with co-existing fecal incontinence, that is, involuntary excretion of fecal material at inappropriate moments or places recurring more than twice a month [2]. We attributed this problem to the pudenda - nerve damage seen on the external sphincter EMG. Pudendal neuropathy is among the main causes of this association, as well as organic damage to the external sphincter, for example after obstetric or surgical anorectal trauma, and prolapse-associated altered stimulation of the anorectal inhibitory reflex.

Because no reference therapeutic standard exists for managing full-thickness rectal prolapsed, especially in patients with co-existing fecal incontinence, in managing our patient's problems we had to select the surgical procedure most likely to repair the rectal prolapse, diminish fecal incontinence, and improve her quality of life. Numerous surgical procedures, including abdominal and perineal approaches, exist for managing rectal prolapse $[3,4]$.

In an older, debilitated person such as the patient in our case, in whom all other treatments was proven ineffective, the most indicated perineal operation is the Altemeier procedure (rectosigmoidectomy), currently combined with anterior levatorplasty. Because this combined technique uses the transanal approach, it has the advantage of being relatively non-invasive. It can also be done rapidly 
(55 to 120 minutes) and leads to low intraoperative blood loss (45 to $180 \mathrm{ml}$ ) [3]. The disadvantages, however, are high recurrence rates, which reach $58 \%$, with a mean value around 6 to $10 \%$ depending on the length of followup $[3,5,6]$ and, because the Altemeier procedure leaves pre-existing fecal incontinence unchanged, a high incidence of postoperative incontinence $(22 \%$ to $56 \%$ of cases) $[6,7]$.

Because the rectal prolapse in our patient co-existed with fecal incontinence for liquids and solids and EMG evidence showed abnormal sphincter function related to pudendal neuropathy, after an Altemeier resection alone this condition would probably have persisted or even worsened. Combining the Altemeier procedure with dynamic graciloplasty therefore proved an appropriate choice because it circumvented these problems.

The use of the nearby gracile muscle to reconstruct the anal sphincter was first described in 1952 [8]. The clinical results of dynamic graciloplasty were later improved by implanting a pacemaker device to stimulate the gracile muscle electrically. The first reported dynamic graciloplasty dates back to $1991[9,10]$. Dynamic graciloplasty is indicated in the treatment of severe fecal incontinence caused by irreparable organic sphincter damage from irreversible neurogenic pudendal nerve damage or congenital disorders. It can also be used for anorectal repair after a Miles abdominoperineal resection. The long-term aim of chronic gracile muscle neurostimulation is to replace voluntary contraction and exert a sustained contraction that transforms fatigue-prone (type II) muscle fibers into the fatigue-resistant (type I) fibers that physiologically account for $80 \%$ of the external sphincter [11]. Electrical stimulation of the neosphincter elicits a forceful tonic contraction yielding basal anal pressures from 56 to 95 $\mathrm{mmHg}$ as assessed by anal manometry. When the patient uses the pulse generator to turn the stimulator off, the neosphincter relaxes thus allowing evacuation.

The improved outcome in fecal continence for solids in this patient at 2 years after combined surgery receives confirmation from multiple studies in patients treated with dynamic graciloplasty alone $[12,13]$. The success rate is at an average of $60 \%$ [3]. Although our patient had none of the reported early complications, including infections and pain in the lower limbs, the possibilities of long-term complications like stimulator malfunction, remains [2].

Of the various therapeutic options available to surgically repair rectal prolapse associated with fecal incontinence, combining the two operations seemed a valid choice in this older, debilitated patient. We considered an artificial anal sphincter an unfeasible option, given the problems in surgical management related to our patient's advanced age and motor deficits and, equally important, the high rates of infection (about 20\%) [14]. Given the EMG findings of severe sphincter denervation, we could not have used sacral nerve neuromodulation, which is an undoubtedly valid technique with a promising future for patients whose incontinence is resistant to conservative measures [15].

\section{Conclusion}

Co-existing full-thickness rectal prolapse and fecal incontinence is an anorectal disorder that is hard to manage. The ideal therapeutic choice depends on numerous factors, such as the patient's general condition and local disease, and the surgeon's expertise in using available surgical techniques. These variables make it difficult to standardize an operative procedure. The combined dynamic graciloplasty and Altemeier operation we propose could be a valid therapeutic option in patients with severe rectal prolapse with fecal incontinence from irreversible neurogenic damage.

\section{Consent}

Written informed consent was obtained from the patient for publication of this case report and any accompanying images. A copy of the written consent is available for review by the Editor-in-Chief of this journal.

\section{Competing interests}

The authors declare that they have no competing interests.

\section{Authors' contributions}

MM and FC analyzed and interpreted the patient's medical data, made the surgical plan and performed the operation. RPI was a major contributor in writing the manuscript and also participated in the surgical operation. AC also contributed in writing the manuscript and participated in the surgical operation. EDE wrote the literature review. All authors read and approved the final manuscript.

\section{References}

I. Woods R, Voyvodic F, Schloithe C, Sage MR, Wattchow A: Anal sphincter tears in patients with rectal prolapse and faecal incontinence. Colorectal Dis 2003, 5:544-548.

2. Chapman AE, Geerdes B, Hewett P, Young J, Eyers T, Kiroff G, Maddern G]: Systematic review of dynamic graciloplasty in the treatment of faecal incontinence. Br J Surg 2002, 89:। $138-153$.

3. Zbar AP, Takashima S, Hasegawa T, Kitabayashi K: Perineal rectosigmoidectomy (Altemeier's procedure): a review of physiology, technique and outcome. Tech Coloproctol 2002, 6:109-1I6.

4. Kim DS, Tsang CB, Wong WD, Lowry AC, Goldberg SM, Madoff RD: Complete rectal prolapse: evolution of management and results. Dis Colon Rectum 1999, 42:460-469.

5. Kimmis MH, Evetts BK, Isler J, Billingham R: The Altemeier repair: outpatient treatment of rectal prolapse. Dis Colon Rectum 200 I, 44:565-570.

6. Prasad ML, Pearl RK, Abcarian H, Orsay CP, Nelson RL: Perineal proctectomy, posterior rectopexy and postanal levator repair for the treatment of rectal prolapse. Dis Colon Rectum 1986, 29:547-552. 
7. Ramanujam $P$, Venkatesh K: Perineal excision of rectal prolapse with posterior levator ani repair in elderly high-risk patient. Dis Colon Rectum 1988, 3 1:704-706.

8. Pickrell KL, Broadbent TR, Masters FW, Metzger JT: Construction of a rectal sphincter and restoration of anal continence by transplanting the gracilis muscle. A report of 4 cases in children. Ann Surg 1952, 135:853-862.

9. Beaten CGMI, Konsten J, Spaans F, Visser R, Habets AM, Bourgeois IM, Wagenmakers AJ, Soeters PB: Dynamic graciloplasty for treatment of faecal incontinence. Lancet 1991, 338: I I63-1 I65.

10. Williams NS, Patel J, George BD, Hallan RI, Watkins ES: Development of an electrically stimulated neoanal sphincter. Lancet 199I, 338: II66-II69.

II. George BD, Williams NS, Patel J, Swash M, Watkins ES: Physiological and histochemical adaptation of the electrically stimulated gracilis muscle to neoanal sphincter function. $\mathrm{Br} J \mathrm{Surg}$ 1993, 80:1342-1346.

12. Cavina E, Seccia M, Banti P, Zocco G: Anorectal reconstruction after abdominoperineal resection. Experience with doublewrap graciloplasty supported by low-frequency electrostimulation. Dis Colon Rectum 1998, 41:1010-1016.

13. Beaten CG, Bailey HR, Bakka A, Belliveau P, Berg E, Buie WD, Burnstein MJ, Christiansen J, Coller JA, Galandiuk S, LaFontaine LJ, Lange J, Madoff RD, Matzel KE, Påhlman L, Parc R, Reilly JC, Seccia M, Thorson AG, Vernava AM, Wexner S: Safety and efficacy of dynamic graciloplasty for faecal incontinence: report of a prospective, multicenter trial. Dynamic Graciloplasty Therapy Study Group. Dis Colon Rectum 2000, 43:743-75I.

14. Devesa JM, Rey A, Hervas PL, Halawa KS, Larranaga I, Svidler L, Abraira $V$, Muriel A: Artificial anal sphincter: complication and functional results of a large personal series. Dis Colon Rectum 2002, 45: II54-II63.

15. Jarret MED, Matzel KE, Stosser M, Beaten CGM, Kamm MA: Sacral nerve stimulation for fecal incontinence following surgery for rectal prolapse repair: a multicenter study. Dis Colon Rectum 2005, 48: I 243-1248.

Publish with Biomed Central and every scientist can read your work free of charge

"BioMed Central will be the most significant development for disseminating the results of biomedical research in our lifetime. "

Sir Paul Nurse, Cancer Research UK

Your research papers will be:

- available free of charge to the entire biomedical community

- peer reviewed and published immediately upon acceptance

- cited in PubMed and archived on PubMed Central

- yours - you keep the copyright

Submit your manuscript here:

http://www.biomedcentral.com/info/publishing_adv.asp
BioMedcentral 